\title{
Correlation between engagement and quality of life at work in Brazilian nursing professionals at the beginning of the Covid-19 pandemic
}

\author{
Taisa Moitinho de Carvalho, ${ }^{1,}$, Luciano Garcia Lourençãoㄹ, Maria Helena Pinto', Renata Andrea Pietro Pereira \\ Viana $^{3}$, Ana Maria Batista da Silva Gonçalves Moreira ${ }^{4}$, Leticia Pepineli de Mello5, Carla Graziela Carvalho Matos ${ }^{4}$, \\ Lucia Marinilza Beccaria ${ }^{1}$, Cristina Prata Amendola ${ }^{4,6}$, Amanda Maria Ribas Rosa de Oliveira ${ }^{5}$, Maria Aurélia da \\ Silveira Assoni ${ }^{4,6}$, Eliana Fazuoli Chubaci, Luciana de Souza Lima ${ }^{7}$, Katia Jaira Galisteu ${ }^{1}$, Francisco Rosemiro \\ Guimarães Ximenes Neto ${ }^{8}$, Natalia Sperli Geraldes Marin dos Santos Sasaki ${ }^{1}$, Maria de Lourdes Sperli Geraldes \\ Santos ${ }^{1}$, Jacqueline Flores de Oliveira ${ }^{2}$, Carlos Leonardo Figueiredo Cunha ${ }^{9}$, Flávio Adriano Borges ${ }^{10}$, Juliana Lima \\ da Cunha ${ }^{2}$
}



Abstract: The aim of the study is to investigate the correlation between engagement and quality of life at work in nursing professionals, from a public hospital in the interior of the state of São Paulo, Brazil, at the beginning of the Covid-19 pandemic. We conducted a cross-sectional, descriptive, and correlational study, with nursing professionals between December 2020 and January 2021. We used the Brazilian versions of the Utrecht Work Engagement Scale and the Walton Model scale. The results showed that nursing professionals presented high scores for absorption (4.9) very high scores for vigor (5.2), dedication (5.6), and an overall score (5.2) for engagement. Most nursing professionals scored intermediate levels for fair and adequate compensation $(51.9 \%)$ satisfactory levels for the other domains, and achieved the highest for social relevance $(76.5 \%)$, for quality of life. Professionals with satisfactory levels of quality of life tended to have higher levels of engagement at work. Professionals were strongly engaged and satisfied with their quality of life at work at the beginning of the Covid-19 pandemic.

Keywords: work engagement; job satisfaction; quality of life; occupational health; nursing practitioners; nursing.

\section{Introduction}

Nursing plays an important role in hospitals internationally. In Brazil, the category is composed of college level professionals (Nurses) and medium/technical level professionals (Nursing Assistants and Technicians) and represents more than two million professionals. There is, however, an unequal distribution of these professionals in the na- 
tional territory, with a higher concentration in the state of São Paulo (25\% of the total) $[1,2]$.

Due to the often-precarious working conditions, nursing workers present with high rates of absence due to psychological changes, such as anxiety, depression, and feelings of devaluation that compromise quality of life, well-being, engagement in work, personal and professional satisfaction, and harm work performance [3-7].

The Covid-19 pandemic raised more concern about the physical and mental health of these professionals, due to work overload. This was due to increased hospitalizations and extended working hours which generated physical and mental fatigue. Moreover, the concern with exposure to the virus, likelihood of contaminating family members, risk of safety equipment shortages and difficulties arising from increased rates of absenteeism further exacerbated the situation. [8-12].

This scenario further increases the responsibility of nursing leaders to create strategies that contribute to increasing team engagement, ensuring sustainable performance, guaranteeing health safety and work quality. These leaders have an opportune moment to make a difference in health institutions, through showing a positive impact of leadership competence and transforming realities [13].

The engagement of the team is congruent with the quality of the relationship between leaders and followers. The support offered by leadership goes beyond human resources policies, as the manager makes policies real and practical. One of the antecedents to the desire of not belonging to the work institution, is being unengaged which can increase employee turnover and generate additional costs, over and above training investments. Thus, retaining trained and qualified employees has an impact on achieving better results $[14,15]$.

Work engagement is defined as a positive and rewarding work-related mental state, which involves the worker's satisfaction with the profession and a sense of well-being. It is characterized by high levels of energy and resilience (vigor), strong identification with work, sense of significance, enthusiasm, inspiration, pride, and challenge (dedication), which generate positive emotions regarding work and good work performance of professionals, resulting in a sense of belonging, satisfaction, and fulfillment (absorption) [15-17].

The process of globalization and technological development makes individuals increasingly depend on the companies in which they work to achieve their life goals, and this depends on the opportunities within the organizations [18]. Therefore, studies on quality of life are gaining greater importance in organizations, motivated by the need to understand the factors that positively influence the lives of workers, in professional and personal relationships. Working conditions, work environment, and excessive workload are some of the factors that result in emotional exhaustion of the individual, which can negatively influence quality of life. [19-21].

Quality of work life (QWL) is directly related to workers' job satisfaction, hygiene in the work environment, physical, mental health and well-being safety, interpersonal relationships, management and leadership style, application of ergonomics in the use of machines, tools, and concern for workers' health. QWL is related to choice of profession and organizational culture, which positively influences the commitment of professionals, and is reflected in organizational success [21-23].

Moreover, as individuals spend most of their lives in their work environments, the events in these places accompany workers beyond the organizations. This can influence their personal life (living with family, friends, and other social activities) or, in a reciprocal manner, personal problems can influence work performance. Therefore, leaders should: encourage the team's professionals to achieve their life projects, assist them to recognize their role and value to the company, encourage them to participate in change processes, provide them with opportunities for professional and individual development [22]. 
As work engagement can influence QWL [16], it is important to understand work engagement levels and QWL of nursing professionals, to better understand their behavior. Moreover, producing knowledge that will subsidize the implementation of actions to improve the performance of the team, will positively impact the commitment of professionals and the quality of care, reduce the turnover of professionals and resulting costs.

Therefore, this study aimed to investigate the correlation between engagement and quality of life at work in nursing professionals from a public hospital in the interior of the state of São Paulo, Brazil, at the beginning of the Covid-19 pandemic.

\section{Materials and Methods}

\subsection{Type of Study}

Cross-sectional, descriptive, and correlational study was conducted between December 2020 and January 2021, with Nursing professionals from a medium-sized philanthropic general hospital (210 beds), located in the countryside of the state of São Paulo, Brazil. It is a reference hospital, which attends to high complexity procedures, women with high-risk pregnancy, neurosurgery, orthopedics, nephrology, cardiovascular surgery, and interventional cardiology procedures. There are 30 adult Intensive Care beds, 10 neonatal and pediatric intensive care beds.

\subsection{Sample and Participants}

The sample was estimated at 284 participants, considering the population of 606 Nursing professionals of the institution (145 nurses, 414 nursing technicians and 47 nursing assistants), confidence level of $95 \%$, margin of error of $5 \%$, reliability of $95 \%$ and an addition of $20 \%$ for losses. Professionals who were on vacation or away from work for any reason during the data collection period, those who did not answer the questionnaires completely, and professionals from an outsourced sector who occupied the physical structure of the institution, however had external managers, were excluded from the study.

All eligible professionals for the study were invited to answer the instruments, which was made available through the Research Electronic Data Capture (REDCap) platform, which respects the criteria established by the General Law of Data Protection. The final sample composed of 341 nursing professionals, including 93 nurses, 217 nursing technicians, 27 nursing assistants, and four professionals who did not reflect their professional category.

\subsection{Procedures, Measurements, Variables and Outcome}

The following three self-applied instruments were used for data collection:

(a) an instrument elaborated by the authors, containing sociodemographic and characterization variables of the professionals, such as: gender, age, marital status, whether they have children or not, education, training period, means of transportation used and time to get to work, position and time of performance in the institution.

(b) the Brazilian version of the Utrecht Work Engagement Scale (UWES) was adapted and validated by Vazques et al. [24]. The UWES consists of 17 questions that evaluate the level of satisfaction of professionals with their work and considers three aspects of work engagement: vigor (six questions), dedication (five questions), and absorption (six questions) [23]. The UWES uses a seven-point Likert scale, where $0=$ never; 1 = almost never; 2 = sometimes; 3 = regularly; $4=$ frequently; $5=$ almost always; $6=$ always. The calculation of the scores was performed using the arithmetic mean of the answers to the questions that composed each dimension, ranging from zero to six [25].

c) an adapted version of the Walton model (QWL) validated in Brazil by Timossi et al. The instrument consists of 32 statements distributed in eight domains: fair and adequate compensation (two statements); working conditions (five statements); use of abilities (five statements); opportunities (four statements); social integration (four statements); constitutionalism (four statements); work and life (three statements) and social 
relevance (five statements) [265]. The QWL questionnaire used a five-point Likert scale, where 1 = strongly disagree; 2 = disagree; 3 = neither disagree nor agree; $4=$ agree; $5=$ strongly agree. The higher the score, considering five as the maximum for the analyzed criterion, the more satisfied the professional [26].

The instruments were made available electronically, through the Research Electronic Data Capture (REDCap) platform, a free software for electronic data capture, which allows the creation of research instruments, provides features for collaboration, metadata workflow, security, auditing, and export to other statistical programs [27]. Two trained nurses voluntarily assisted the main researcher with data collection. In the explanation that preceded the application of the Consent Term, it was emphasized that the study was anonymous and did not present conflicts of interest with hospital administration. Subsequently, professionals were instructed to access the questions by means of a "QRCode" image. A link was sent via WhatsApp application to those who were unable to access the QRCode, without revealing participant identity. Data were collected between December 2020 and January 2021. Participants had access to the questionnaire after reading and signing the Informed Consent Form and thus agreed to participate in the study. The information required to answer the questionnaire was made available before each block of questions. The time frame to respond to the instruments was clarified.

\subsection{Statistical Analysis}

The data collected were tabulated and analyzed with the software IBM-SPSS, version 27.0 for Windows (SPSS, Inc., Chicago, IL, USA). Descriptive (relative and absolute frequencies, means, and standard deviations) and inferential (ANOVA and Correlation test) measures were applied, considering a significance level of $5 \%(p<0.05)$.

The mean scores for the dimensions of the UWES scale were calculated for work engagement: overall score (17 questions), vigor (questions 1, 4, 8, 12, 15 and 17), dedication (questions 2,5,7,10, and 13) and absorption (questions 3, 6, 9, 11, 14 and 16), according to the statistical model proposed in the Preliminary Manual UWES - Utrecht Work Engagement Scale [25]. The mean values were interpreted according to the manual's decoding ranges: 0 to $0.99=$ Very Low; 1 to $1.99=$ Low; 2 to $3.99=$ Medium; 4 to $4.99=$ High; 5 to 6 = Very High.

Quality of life at work was analyzed by calculating a mean score for the eight domains of the scale. The average scores obtained on a scale of one to five were converted into a scale of 0 to 100, allowing the classification of the quality-of-life level into: Unsatisfactory (scores between 0 and 24.99), Intermediate (scores between 25 and 75), and Satisfactory (scores between 75.1 and 100) [26].

Pearson's correlation test was used to analyze the correlation between engagement and quality of life at work, considering weak correlation for $r$ values up to 0.39 , moderate for values between 0.40 and 0.69 , and strong for values equal to or greater than 0.70 .

\subsection{Ethical Considerations}

Ethical approval for this study was obtained from the institutional ethics committee (decision: 4,349,861 - October 20, 2020; CAAE: 14262719.2.3001.5437). Informed consent was received from all participants before participating in the study. All procedures performed in this study were compatible with the ethical standards of the institutional research committee and with those of the Declaration of Helsinki and its comparable ethical standards.

\section{Results}

A total of 341 nursing professionals participated in the study: 93 (27.3\%) nurses, 27 (7.9\%) nursing assistants and 217 (63.6\%) nursing technicians. The sociodemographic analysis showed that $89.4 \%$ of the participants were female, $73.3 \%$ were between 21 and 40 years, $49.3 \%$ were married or in a stable relationship, $60.4 \%$ had children; $29.0 \%$ had between one and less than four years of graduation, and $27.6 \%$ had graduated more than 
10 years ago. Most professionals had worked at the institution for less than four years, and $34.9 \%$ had between one and less than four years of experience in the hospital (Table $1)$.

Table 1. Sociodemographic and professional characteristics of study participants in Brazil.

\begin{tabular}{lcc}
\hline \multicolumn{1}{c}{ Variables } & n & \% \\
\hline Professional Category & & \\
Nursing Auxiliary & 27 & 7.9 \\
Nursing Technician & 217 & 63.6 \\
Nurse & 93 & 27.3 \\
No answer & 4 & 1.2
\end{tabular}

Sex

Female

$305 \quad 89.4$

Male

$33 \quad 9.7$

No answer

3

0.9

Age Group (years)

$$
\leq 20
$$

$6 \quad 1.8$

21 a 30

$123 \quad 36.1$

31 a 40

$127 \quad 37.2$

41 a 50

$60 \quad 17.6$

$\geq 51$

$15 \quad 4.4$

No answer

$\begin{array}{ll}10 & 2.9\end{array}$

\section{Marital Status}

Married / Stable Union

$168 \quad 49.3$

Single

$134 \quad 39.3$

Divorced/ Separated

$31 \quad 9.1$

Widowed

$5 \quad 1.5$

No answer

3

0.9

Sons

Yes

$206 \quad 60.4$

No

$131 \quad 38.4$

No answer

4

1.2

Time of Formation (in years)

$<1$

$30 \quad 8.8$

$\geq 1$ e $<4$

$99 \quad 29.0$

$\geq 4$ e $<7$

$57 \quad 16.7$

$\geq 7$ e $<10$

$57 \quad 16.7$

$>10$

$94 \quad 27.6$

No answer

Time of performance in the Institution (in years) 


\begin{tabular}{lcc}
$\geq 1 \mathrm{e}<4$ & 119 & 34.9 \\
$\geq 4 \mathrm{e}<7$ & 60 & 17.6 \\
$\geq 7 \mathrm{e}<10$ & 37 & 10.9 \\
$\geq 10$ & 60 & 17.6 \\
No answer & 2 & 0.6 \\
\hline
\end{tabular}

The results for work engagement of nursing professionals showed high mean scores for absorption (4.9) very high scores for vigor (5.2), dedication (5.6), and an overall score (5.2) (Table 2).

Table 2. Evaluation of work engagement of nursing professionals in Brazil.

\begin{tabular}{lccccccc}
\hline $\begin{array}{c}\text { UWES* } \\
\text { Dimensions }\end{array}$ & ${ }^{\dagger}$ Min & $\ddagger$ Max & \$Md & Mean & $\begin{array}{c}\text { Standard } \\
\text { Deviation }\end{array}$ & CI 95\% & Interpretation \\
\hline Vigor & 1.7 & 6.0 & 5.3 & 5.2 & 0.8 & $5.1-5.2$ & Very high \\
Dedication & 2.0 & 6.0 & 5.8 & 5.6 & 0.6 & $5.5-5.7$ & Very high \\
Absorption & 1.3 & 6.0 & 5.0 & 4.9 & 0.9 & $4.8-5.0$ & High \\
Overall score & 1.7 & 6.0 & 5.4 & 5.2 & 0.6 & $5.1-5.3$ & Very high \\
\hline
\end{tabular}

*UWES: Utrecht Work Engagement Scale; ${ }^{+}$Min: minimum; $¥$ Max: maximum; $\S M d$ : median; ${ }^{\natural} C I$ 95\%: 95\% confidence interval.

Most professionals obtained intermediate levels of QOL in the domain, fair and appropriate compensation $(51.9 \%)$, satisfactory levels in the other domains and the highest score $(76.5 \%)$ for social relevance domain, when assessing quality of work life . (Table 3).

Table 3. Distribution of nursing professionals, according to the level of quality of life at work in Brazil.

\begin{tabular}{lccc}
\hline \multirow{2}{*}{ QLW Domains } & \multicolumn{3}{c}{ QWL Level } \\
\cline { 2 - 4 } & Unsatisfactory & Intermediate & Satisfactory \\
\cline { 2 - 4 } & $\mathbf{n}(\%)$ & $\mathbf{n ~ ( \% )}$ & $\mathbf{n ~ ( \% )}$ \\
\hline Fair and adequate & $19(5.6)$ & $176(51.9)$ & $144(42.5)$ \\
compensation & $5(1.5)$ & $137(40.3)$ & $199(58.4)$ \\
Working conditions & $3(0.9)$ & $106(31.1)$ & $232(68.0)$ \\
Use of skills & $6(1.8)$ & $155(45.5)$ & $180(52.8)$ \\
Opportunity & $4(1.2)$ & $102(29.9)$ & $235(68.9)$ \\
Social Integration & $8(2.3)$ & $111(32.6)$ & $222(65.1)$ \\
Constitutionalism & $4(1.2)$ & $140(41.1)$ & $197(57.8)$ \\
Work and Life & $3(0.9)$ & $77(22.6)$ & $261(76.5)$ \\
Social relevance & &
\end{tabular}

The analysis of the correlation between quality of life and work engagement, presented in Table 4, showed a strong and positive correlation between the social integration domain of QOL and vigor dimension of work engagement $(\mathrm{r}=0.88 ; \mathrm{p}=<0.001)$; moderate positive correlation between QWL working conditions domain and vigor ( $\mathrm{r}=0.40$; $\mathrm{p}=<0.001)$, dedication $(\mathrm{r}=0.40 ; \mathrm{p}=<0.001)$ and an overall score $(\mathrm{r}=0.41 ; \mathrm{p}=<0.001)$ for dimensions of work engagement. The correlations were positive and weak for the other domains of QOL and dimensions of work engagement (Table 4). 
We also observed a tendency for professionals with satisfactory levels of quality of life to have higher levels of work engagement. It is noteworthy, however, that professionals with unsatisfactory levels of social integration, constitutionalism, and social relevance had higher levels of engagement (overall score) and absorption. Professionals with unsatisfactory levels of work and life showed higher levels of absorption (Table 4).

Table 4. Analysis of the relationship between engagement and quality of life at work in nursing professionals in Brazil.

\begin{tabular}{|c|c|c|c|c|}
\hline \multirow{3}{*}{ QWL Domains } & \multicolumn{4}{|c|}{ Dimensions of Work Engagement } \\
\hline & Vigor & Dedication & Absorption & General Score \\
\hline & Mean (SD) & Mean (SD) & Mean (SD) & Mean (SD) \\
\hline \multicolumn{5}{|c|}{ Fair and adequate compensation } \\
\hline Unsatisfactory & $4.4(1.2)^{b}$ & $5.0(1.1)^{c}$ & $4.4(1.3)^{b}$ & $4.6(1.1)^{b}$ \\
\hline Intermediate & $5.0(0.8)^{c}$ & $5.6(0.6)^{c}$ & $4.8(0.9)^{\mathrm{b}}$ & $5.1(0.6)^{c}$ \\
\hline Satisfactory & $5.4(0.5)^{c}$ & $5.8(0.5)^{c}$ & $5.1(0.7)^{c}$ & $5.4(0.4)^{c}$ \\
\hline$p$-value (ANOVA) & $<0.001$ & $<0.001$ & $<0.001$ & $<0.001$ \\
\hline Correlation Coefficient $(r)$ & $0.31 \S$ & $0.35 \&$ & $0.20 \S$ & $0.32 \S$ \\
\hline p-value (Pearson test) & $<0.001$ & $<0.001$ & $<0.001$ & $<0.001$ \\
\hline \multicolumn{5}{|l|}{ Working conditions } \\
\hline Unsatisfactory & $5.3(0.8)^{c}$ & $5.6(0.5)^{c}$ & $5.1(0.7)^{c}$ & $5.3(0.6)^{c}$ \\
\hline Intermediate & $4.8(0.9)^{b}$ & $5.3(0.8)^{c}$ & $4.6(1.1)^{\mathrm{a}}$ & $4.9(0.8)^{b}$ \\
\hline Satisfactory & $5.4(0.5)^{c}$ & $5.8(0.3)^{c}$ & $5.1(0.7)^{c}$ & $5.4(0.4)^{c}$ \\
\hline$p$-value (ANOVA) & $<0.001$ & $<0.001$ & $<0.001$ & $<0.001$ \\
\hline Correlation Coefficient $(r)$ & $0.40+t$ & $0.40+t$ & $0.27 \S$ & $0.41+t$ \\
\hline p-value (Pearson test) & $<0.001$ & $<0.001$ & $<0.001$ & $<0.001$ \\
\hline \multicolumn{5}{|l|}{ Use of skills } \\
\hline Unsatisfactory & $3.9(2.2)^{\mathrm{a}}$ & $4.3(2.1)^{b}$ & $3.7(0.2)^{\mathrm{a}}$ & $4.0(2.1)^{b}$ \\
\hline Intermediate & $4.8(0.9)^{b}$ & $5.4(0.7)^{c}$ & $4.7(1.0)^{b}$ & $4.9(0.8)^{b}$ \\
\hline Satisfactory & $5.3(0.6)^{c}$ & $5.7(0.5)^{c}$ & $5.0(0.8)^{c}$ & $5.3(0.5)^{c}$ \\
\hline$p$-value (ANOVA) & $<0.001$ & $<0.001$ & 0.010 & $<0.001$ \\
\hline Correlation Coefficient ( $r$ ) & $0.35 \S$ & $0.35 \S$ & $0.21 \S$ & $0.34 \S$ \\
\hline p-value (Pearson test) & $<0.001$ & $<0.001$ & $<0.001$ & $<0.001$ \\
\hline \multicolumn{5}{|l|}{ Opportunity } \\
\hline Unsatisfactory & $4.2(1.6)^{b}$ & $4.8(1.5)^{b}$ & $4.4(1.7)^{\mathrm{b}}$ & $4.5(1.6)^{b}$ \\
\hline Intermediate & $5.0(0.8)^{c}$ & $5.4(0.7)^{c}$ & $4.6(1.0)^{b}$ & $5.0(0.7)^{c}$ \\
\hline Satisfactory & $5.4(0.7)^{c}$ & $5.8(0.3)^{c}$ & $5.1(0.7)^{c}$ & $5.4(0.4)^{c}$ \\
\hline$p$-value (ANOVA) & $<0.001$ & $<0.001$ & 0.010 & $<0.001$ \\
\hline Correlation Coefficient $(r)$ & $0.36 \S$ & $0.36 \S$ & $0.26 \S$ & $0.37 \S$ \\
\hline p-value (Pearson test) & $<0.001$ & $<0.001$ & $<0.001$ & $<0.001$ \\
\hline \multicolumn{5}{|l|}{ Social Integration } \\
\hline Unsatisfactory & $5.1(0.9)^{c}$ & $5.7(0.6)^{c}$ & $5.3(0.8)^{c}$ & $5.4(0.7)^{c}$ \\
\hline Intermediate & $4.9(1.0)^{b}$ & $5.3(0.9)^{c}$ & $4.6(1.1)^{\mathrm{b}}$ & $4.9(0.9)^{b}$ \\
\hline Satisfactory & $5.3(0.6)^{c}$ & $5.7(0.4)^{c}$ & $5.0(0.8)^{c}$ & $5.3(0.4)^{c}$ \\
\hline$p$-value (ANOVA) & 0.008 & $<0.001$ & 0.032 & 0.003 \\
\hline
\end{tabular}




\begin{tabular}{|c|c|c|c|c|}
\hline Correlation Coefficient ( $r$ ) & $0.88^{¥}$ & $0.29 \S$ & $0.19 \S$ & $0.28 \S$ \\
\hline p-value (Pearson test) & $<0.001$ & $<0.001$ & $<0.001$ & $<0.001$ \\
\hline \multicolumn{5}{|l|}{ Constitutionalism } \\
\hline Unsatisfactory & $5.3(0.7)^{c}$ & $5.7(0.4)^{c}$ & $5.4(0.7)^{c}$ & $5.4(0.5)^{c}$ \\
\hline Intermediate & $4.8(1.0)^{b}$ & $5.3(0.8)^{c}$ & $4.6(1.1)^{b}$ & $4.9(0.9)^{b}$ \\
\hline Satisfactory & $5.3(0.6)^{c}$ & $5.8(0.4)^{c}$ & $5.0(0.7)^{c}$ & $5.3(0.4)^{c}$ \\
\hline$p$-value (ANOVA) & $<0.001$ & $<0.001$ & $<0.001$ & $<0.001$ \\
\hline Correlation Coefficient $(r)$ & $0.35 \S$ & $0.35 \S$ & $0.21 \S$ & $0.33 \S$ \\
\hline p-value (Pearson test) & $<0.001$ & $<0.001$ & $<0.001$ & $<0.001$ \\
\hline \multicolumn{5}{|l|}{ Work and Life } \\
\hline Unsatisfactory & $5.3(0.8)^{c}$ & $5.7(0.6)^{c}$ & $5.4(0.8)^{c}$ & $5.4(0.7)^{\mathrm{c}}$ \\
\hline Intermediate & $4.9(0.9)^{b}$ & $5.4(0.8)^{c}$ & $4.7(1.0)^{b}$ & $5.0(0.8)^{c}$ \\
\hline Satisfactory & $5.3(0.6)^{c}$ & $5.8(0.4)^{c}$ & $5.0(0.7)^{c}$ & $5.4(0.5)^{\mathrm{c}}$ \\
\hline$p$-value (ANOVA) & $<0.001$ & $<0.001$ & 0.002 & $<0.001$ \\
\hline Correlation Coefficient ( $r$ ) & $0.31 \S$ & $0.28 \S$ & $0.18 \S$ & $0.29 \S$ \\
\hline p-value (Pearson test) & $<0.001$ & $<0.001$ & 0.001 & $<0.001$ \\
\hline \multicolumn{5}{|l|}{ Social relevance } \\
\hline Unsatisfactory & $5.3(1.0)^{c}$ & $5.5(0.6)^{c}$ & $5.2(0.9) \mathrm{c}$ & $5.4(0.9)^{c}$ \\
\hline Intermediate & $4.6(1.0)^{\mathrm{b}}$ & $5.2(0.9)^{c}$ & $4.4(1.1)^{b}$ & $4.7(0.9)^{b}$ \\
\hline Satisfactory & $5.3(0.6)^{c}$ & $5.8(0.4)^{c}$ & $5.0(0.8)^{c}$ & $5.3(0.5)^{c}$ \\
\hline$p$-value (ANOVA) & $<0.001$ & $<0.001$ & $<0.001$ & $<0.001$ \\
\hline Correlation Coefficient $(r)$ & $0.36 \S$ & $0.38 \S$ & $0.24 \S$ & $0.36 \&$ \\
\hline$p$-value (Pearson test) & $<0.001$ & $<0.001$ & $<0.001$ & $<0.001$ \\
\hline
\end{tabular}

${ }^{a}$ Low level of engagement. ${ }^{b}$ Medium level of engagement. ${ }^{c}$ High level of engagement. $\S$ Weak correlation. $t \uparrow$ Moderate correlation. ${ }^{¥}$ Strong correlation.

\section{Discussion}

The sociodemographic profile of nursing professionals in this study corroborates other studies and is consistent with the profile of Brazilian nursing professionals, which highlights the predominance of nursing technicians and female prevalence in the profession $[2,4-6,29,30]$, despite the trend of increasing male professionals in this professional category [310].

The evaluation of the levels of engagement of nursing professionals showed that they have an important sense of concentration and pleasure, which connects these nursing professionals to work, as well as very high levels of energy and mental resilience, involvement, and enthusiasm with work. These results are consistent with other studies on work engagement with Brazilian nursing professionals [28,29] from other countries [32-35], and evidence that professionals were highly engaged and aligned with the work environment and activity at the beginning of the COVID-19 pandemic. Maintaining engagement requires articulation between personal and professional capacities, and the autonomy of the professional in the workplace [35].

Similarly, it was observed that most professionals presented satisfactory levels of QWT, especially in relation to workers' perception of the hospital's social responsibility, quality of services provided, and workers' care. These results show that the company's investment in adequate conditions for employee well-being that favor development and organizational justice contribute to increased quality of life and worker engagement $[35,36]$. 
Moreover, we observed that the professionals evaluated presented intermediate levels of QWL and related it to the adequacy of remuneration to work and equity criteria. This is a sensitive situation for all Brazilian nursing professionals, who are negatively impacted by wage inequalities and poor remuneration [37,38], leading them to retain more than one job. Associated with long working hours, the impairment of QWL related to the perception of fair and adequate compensation can exacerbate physical and emotional exhaustion, impairing the professional's performance [39-41].

However, we emphasize that although engagement is considered a stable phenomenon, it is related to organizational and work characteristics [42,43]. Therefore, we believe that engagement levels of the professionals evaluated may have changed since the time of this evaluation, as the health scenario generated by the Covid-19 pandemic has negatively impacted the work process in health services [44-46].

The tendency that professionals with satisfactory levels of quality of life showed higher levels of engagement at work shows the importance of the company investing in programs and actions that increase worker satisfaction, improve interpersonal relationships, well-being, and physical and mental health of workers. Effective actions of valorization and attention to the workers' health positively impacts the desire to remain in the company and decrease the costs associated with turnover and absenteeism [47].

However, periods of intense labor demands can cause physical and emotional fragility, as experienced during the COVID-19 pandemic. During these times, an increase in worker engagement may increase, although there may be unsatisfactory perception of some aspects that compromise work life quality [48]. This may explain the presence of professionals with unsatisfactory levels of social integration, constitutionalism, and social relevance with higher levels of absorption (concentration and attention) and engagement (enthusiasm, attention, and euphoria).

Similarly, we believe that the high level of absorption displayed by workers with unsatisfactory levels of work and life is due to the impact of the COVID-19 pandemic. During this period, the uncertainties related to lack of information about the risks of transmission and death, negatively influenced other spheres of health workers' lives, like their relationships with their families. COVID-19 pandemic resulted in professionals immersing themselves in work and they experienced difficulties to disengaging from the work environment $[48,49]$.

Engagement is a mediating variable in the relationship between organizational justice and organizational citizenship behaviors, that is, when employees are treated fairly, equitably, with dignity and respect, they may feel more engaged in their jobs [50].

Job satisfaction is significantly related to the psychological empowerment of nursing professionals. This empowerment is manifested through four cognitive experiences: meaning, competence, self-determination, and impact. Competence has similarity with the domain use of abilities, of QOL [51]. This relationship was evidenced in our study, which indicated lower levels of engagement among professionals with unsatisfactory level of skill use, while professionals who presented satisfactory level of skill use had higher engagement at work.

The main limitation of this study is related to the cross-sectional design, which does not allow establishing cause and effect relationships. However, its results make a great contribution by presenting a diagnosis of the relationship between engagement and QOL in nursing professionals at the beginning of the Covid-19 pandemic. Thus, the knowledge produced will support future analyses and discussions about the impact of the overload and physical and emotional stress caused by the Covid-19 pandemic on the levels of engagement and QOL of these professionals.

\section{Conclusions}

The study showed that nursing professionals were strongly engaged and satisfied with their quality of life at work at the beginning of the Covid-19 pandemic. 
Work engagement showed a positive correlation with QOL, reinforcing the importance of health institutions to create strategies for valuing nursing professionals, based on aspects that influence job satisfaction and engagement.

Moreover, it is evident that the precariousness of resources experienced by most Brazilian health institutions and evidenced by the COVID-19 pandemic, reinforces the need to devise strategies that raise QWL and work engagement of nursing professionals, such as work recognition and appreciation.

We suggest that new studies be developed after the pandemic, to evaluate its impact on the levels of engagement and quality of work life of nursing professionals who worked on the front line.

Author Contributions: Conceptualization, T.M.C. and M.H,P.; methodology, T.M.C., L.G.L. and M.H.P.; software, T.M.C. and L.G.L.; validation, T.M.C., L.G.L., M.H.P., R.A.P.P.V., A.M.B.S.G.M., L.P.M., C.G.C.M., L.M.B., C.P.A., A.M.R.R.O., M.A.S.A., E.F.C., L.S.L., K.J.G., F.R.G.X.N., N.S.G.M.S.S., M.L.S.G.S., J.F.O., C.L.F.C., F.A.B., and J.L.C.; formal analysis, T.M.C., L.G.L. and M.H.P.; investigation, T.M.C. and M.H.P.; resources, T.M.C., L.G.L. and M.H.P.; data curation, T.M.C., L.G.L. and M.H.P.; writing - original draft preparation, T.M.C. and L.G.L.; writing - review and editing, R.A.P.P.V., A.M.B.S.G.M., L.P.M., C.G.C.M., L.M.B., C.P.A., A.M.R.R.O., M.A.S.A., E.F.C., L.S.L., K.J.G., F.R.G.X.N., N.S.G.M.S.S., M.L.S.G.S., J.F.O., C.L.F.C., F.A.B., and J.L.C.; visualization, T.M.C., L.G.L., M.H.P., R.A.P.P.V., A.M.B.S.G.M., L.P.M., C.G.C.M., L.M.B., C.P.A., A.M.R.R.O., M.A.S.A., E.F.C., L.S.L., K.J.G., F.R.G.X.N., N.S.G.M.S.S., M.L.S.G.S., J.F.O., C.L.F.C., F.A.B., and J.L.C.; supervision, L.G.L. and M.H.P.; project administration, T.M.C. and M.H,P. All authors have read and agreed to the published version of the manuscript.

Funding: This research received no external funding.

Institutional Review Board Statement: The study was conducted according to the guidelines of the Declaration of Helsinki and the study was approved by the Research Ethics Committee at School of Medicine of São José do Rio Preto (decision: 4,349,861; CAAE: 14262719.2.3001.5437) on October 20, 2020.

Informed Consent Statement: Informed consent was obtained from all subjects involved in the study.

Data Availability Statement: The datasets generated during the current study are not publicly available but are available from the corresponding author on reasonable request.

Conflicts of Interest: The authors declare no conflict of interest.

\section{References}

1. Silva, M.C.N.; Machado, M.H. Health and Work System: challenges for the Nursing in Brazil. Ciênc. Saúde Colet 2020, 25, 7-13. https://doi.org/10.1590/1413-81232020251.27572019

2. Conselho Federal de Enfermagem (BR). Enfermagem em números. COFEN, 2019. Available online: http://www.cofen.gov.br/enfermagem-em-numeros (accessed on 20 Jan 2022).

3. Oliveira, D.M.; Alencar, N.M.B.M.; Costa, J.P.; Fernandes, M.A.; Gouveia, M.T.O.; Santos, J.D.M. Afastamento do trabalho por transtornos mentais e comportamentais entre profissionais de enfermagem. Rev. cuid. 2019, 10 , e631. https://doi.org/10.15649/cuidarte.v10i2.631

4. Lourenção, L.G.; Silva, R.A.S.; Moretti, M.S.R.; Sasaki, N.S.G.M.S.; Sodré, P.C.; Gazetta, C.E. Career commitment and entrenchment among Primary Care nurses. Rev. esc. enferm. USP 2021, 55, e20210186. https://doi.org/10.1590/1980-220X-REEUSP-2021-0186

5. Julio, R.S.; Lourenção, L.G.; Penha, J.G.M.; Oliveira, A.M.N.; Nascimento, V.F.; Oliveira, S.M.; Gazetta, C.E. Anxiety, depression, and work engagement in Primary Health Care nursing professionals. Rev Rene 2021, 22, e70762. http://dx.doi.org/10.15253/2175-6783.20212270762 
6. Julio, R.S.; Lourenção, L.G.; Oliveira, S.M.; Farias, D.H.R.; Gazetta, C.E. Prevalence of anxiety and depression in Brazilian Primary Health Care workers. Cad. Bras. Ter. Ocup. 2022, 30 , e2997. https://doi.org/10.1590/2526-8910.ctoAO22712997

7. Azevedo, J.N.L.; Silva, R.F.; Macêdo, T.T.S. Principais causas de absenteísmo na equipe de enfermagem: revisão bibliográfica. Rev Enferm Contemp 2019, 8, 80-86. http://dx.doi.org/10.17267/2317-3378rec.v8i1.1611

8. Kunrath, G.M.; Santarem, M.D.; Oliveira, J.L.C.; Machado, M.L.P.; Camargo, M.P.; Rosa, N.G.; Almeida, V.M.; Vieira, L.B. Predictors associated with absenteeism-disease among Nursing professionals working in an emergency hospital service. Rev. gaúch. enferm 2021, 42, e20190433. https://doi.org/10.1590/1983- 1447.2021.20190433

9. Dal'Bosco, E.B.; Floriano, L.S.M.; Skupien, S.V.; Arcaro, G.; Martins, A.R.; Anselmo, A.C.C. Mental health of nursing in coping with COVID-19 at a regional university hospital. Rev Bras Enferm 2020, 73, e20200434. http://dx.doi.org/10.1590/0034-7167-2020-0434

10. Teixeira, C.F.S.; Soares, C.M.; Souza, E.A.; Lisboa, E.S.; Pinto, I.C.M.; Andrade, L.R.; Espiridião, M.A. The health of healthcare professionals coping with the Covid-19 pandemic. Ciênc. Saúde Colet 2020, 25, 3465-3474. https://doi.org/10.1590/1413-81232020259.19562020

11. Miranda, F.M.A.; Santana L.L.; Pizzolato A.C.; Saquis L.M.M. Working conditions and the impact on the health of the nursing professionals in the context of covid-19. Cogitare enferm 2020; 25 , e72702. http://dx.doi.org/10.5380/ce.v25i0.72702

12. Souza, L.P.S.; Souza, A.G. Enfermagem brasileira na linha de frente contra o novo Coronavírus: quem cuidará de quem cuida? J. nurs. health 2020, 10, e20104005. Available online: https:/periodicos.ufpel.edu.br/ojs2/index.php/enfermagem/article/view/18444/11237 (accessed on 20 Jan 2022 ).

13. Van Kraaij, J.; Van Oostveen, C.; Vermeulen, H.; Heinen, M.; Huis, A.; Adriaansen, M.; Peters, J. Nurse practitioners' perceptions of their ability to enact leadership in hospital care. J. clin. nurs 2020, 29, 447-458. https://doi.org/10.1111/jocn.15105

14. Oliveira, L.B.; Rocha, J.D.C. Engajamento no trabalho: antecedentes individuais e situacionais e sua relação com a intenção de rotatividade. Rev. Bras. de Gestao de Negocios 2017, 19, 415-431. https://doi.org/10.7819/rbgn.v19i64.3373

15. Rotta, D.S.; Lourenção, L.G.; Gonsalez, E.G.; Teixeira, P.R.; Gazetta, C.E.; Pinto, M.H. Engagement of multi-professional residents in health. Rev Esc Enferm USP 2019, 53, e03437. http://dx.doi.org/10.1590/S1980-220X2018003103437

16. Remegio, W.; Rivera, R.R.; Griffin, M.Q.; Fitzpatrick, J.J. The Professional Quality of Life and Work Engagement of Nurse Leaders. Nurse lead 2021, 19, 95-100. http://dx.doi.org/10.1016/j.mnl.2020.08.001

17. Magnan, E.S.; Vazquez, A.C.S.; Pacico, J.C.; Hutz, C.S. Normatização da versão Brasileira da Escala Utrecht de Engajamento no Trabalho. Aval. psicol 2016, 15, 133-140. http://doi.org/10.15689/ap.2016.1502.01

18. Casagrande, D.J. A gestão de pessoas como impulsionadora do desenvolvimento estratégico das organizações brasileiras contemporâneas. Rev Interface Tecnol 2017, 14, 64-75. https://doi.org/10.31510/infa.v14i2.177

19. Wong, I.A.; Wan, Y.K.P.; Gao, J.H. How to attract and retain Generation Y employees? An exploration of career choice and the meaning of work. Tour. Manag. Perspect. 2017, 23, 140-150. https://doi.org/10.1016/j.tmp.2017.06.003

20. Gonsalez, E.G.; Lourenção, L.G.; Teixeira, P.R.; Rotta, D.S.; Gazetta, C.E.; Beretta, D.; Pinto, M.H. Work engagement in employees at professional improvement programs in health. Cad. Bras. Ter. Ocup. 2017, $25,509-517$. https://doi.org/10.1016/10.4322/2526-8910.ctoAO0987

21. Wang, X.; Liu, L.; Zou, F.; Hao, J.; Wu, H. Associations of Occupational Stressors, Perceived Organizational Support, and Psychological Capital with Work Engagement among Chinese Female Nurses. Biomed Res. Int 2017, 5284628. https://doi.org/10.1155/2017/5284628 
22. Moloney, W.; Fieldes, J.; Jacobs, S. An Integrative Review of How Healthcare Organizations Can Support Hospital Nurses to Thrive at Work. Int. j. environ. res. public health 2020, 17, https://doi.org/10.3390/ijerph17238757

23. Nazario, M.; Klimeck, K.A. Qualidade de vida e engajamento no trabalho: Uma análise em uma cooperativa de assistência à saúde. Rev gestão e org cooperativas 2016, 3, 43-56. https://doi.org/10.5902/2359043221493

24. Vazquez, A.C.S.; Magnan, E.D.S.; Pacico, J.C.; Hutz, C.S.; Schaufeli, W.B. Adaptation and Validation of the Brazilian Version of the Utrecht Work Engagement Scale. Psico USF 2015, 20, 207-217. https://doi.org/10.1590/1413-82712015200202

25. Schaufeli, W.; Bakker, A. Escala de Engagement no Trabalho de Utrecht - Manual. Agnst, R.; Benevides-Pereira, A.M.T.; Porto-Martins, P.C. (Translators). GEPEB: Curitiba, Brazil, 2009. Available online: https://www.wilmarschaufeli.nl/publications/Schaufeli/Test\%20Manuals/Test manual UWES Brazil.pdf (accessed on 20 Jan 2022).

26. Timossi, L.; Pedroso, B.; Pilatti, L.; Francisco, A. Walton's model adaptation for quality of work life evaluation. J Phys Educ 2009, 20, 395-405. https://doi.org/10.4025/reveducfis.v20i3.5780

27. Wright, A. REDCap: A Tool for the Electronic Capture of Research Data. J. Electron. Resour. Med. Libr 2016, 14, 197-201, https://doi.org/10.1080/15424065.2016.1259026

28. Silva, A.G.; Cabrera, E.M.S.; Gazetta, C.E.; Sodré, P.C.; Castro, J.R.; Cordioli Jr, J.R.; Cordioli, D.F.C.; Lourenção, L.G. Engagement in primary health care nurses: A cross-sectional study in a Brazilian city. Public Health Nurs 2020, 37, 169-177. http://dx.doi.org/10.1111/phn.12694

29. Lourenção, L.G. Work engagement among participants of residency and professional development programs in nursing. Rev Bras Enferm 2018, 71, 1487-1492. https://doi.org/10.1590/0034-7167-2017-0278

30. Machado, M.H.; Aguiar Filho, W.; Lacerda, W.F.; Oliveira, E.; Lemos, W.; Wermelinger, M.; Vieira, M.; Santos, M.R.; Souza Junior, P.B.; Justino, E.; Barbosa, C. Características gerais da enfermagem: o perfil sócio demográfico. Enferm. Foco 2016, 7, 9-14. https://doi.org/10.21675/2357-707X.2016.v7.nESP.686

31. Manning, J. The Influence of Nurse Manager Leadership Style on Staff Nurse Work Engagement. J. Nurs. Manag 2017, 47, S43-S8. https://doi.org/10.1097/NNA.0000000000000372

32. Maio, T.M. Bullying e Engagement em Enfermeiros. Master's Thesis, Porto School of Nursing, Porto, Portugal, 2016. Available online: http://hdl.handle.net/10400.26/17531 (accessed on 20 Jan 2022).

33. Aboshaiqah, A.E.; Hamadi, H.Y.; Salem, O.A.; Zakari, N.M.A. The work engagement of nurses in multiple hospital sectors in Saudi Arabia: a comparative study. J Nur Manag 2016, 24, 540-548. http://dx.doi.org/10.1111/jonm.12356

34. Merino, C.F.; Gallardo, R.Y. Describiendo el engagement en profesionales de enfermería de atención primaria de salud. Cienc Enferm 2014, 20, 131-140. Available https://scielo.conicyt.cl/scielo.php?script=sci arttext\&pid=S0717-95532014000300012\&lng=en\&nrm=iso\&tlng=en (accessed on 20 Jan 2022).

35. Silva, M.; Borges, E.; Baptista, P.; Queirós, C. Engagement e satisfação dos enfermeiros do pré-hospitalar. Rev. port. enferm. saúde mental 2020, 7, 25-30. https://doi.org/10.19131/rpesm.0243

36. Vidal-Blanco, G.; Oliver, A.; Galiana, L.; Sansó, N. Quality of work life and self-care in nursing staff with high emotional demand. Enferm. clín 2019, 29, 186-194. https://doi.org/10.1016/j.enfcli.2018.06.004

37. Silva, A.G.I.; Mendonça, S.E.S.; Moraes, A.C.; Vasconcelos, T.S.; Costa, G.F. Satisfaction and dissatisfaction of the nursing team in urgent and emergency units: integrative review. Nursing (São Paulo) 2021, 24, 5656-5669, https://doi.org/10.36489/nursing.2021v24i276p5656-5669

38. Sousa, C.N.S.; Silva, F.B.; Silva, J.L.; Santos, A.J.A.; Rocha, E.P.; Mello, F.R.F.; Gedrat, D.C.; Alves, G.G. Análise do estresse ocupacional na enfermagem: revisão integrativa. Rev. Eletrônica Acervo Saúde 2020, 52, e3511. https://doi.org/10.25248/reas.e3511.2020 
39. Chung, Y.; Kim, H.; Koh, D.H.; Park, J.P.; Yoon, S. Relationship Between Shift Intensity and Insomnia Among Hospital Nurses in Korea: A Cross-sectional Study. J. prev. med. public health 2021, 54, 46-54. https://doi.org/10.3961/jpmph.20.555

40. Baldoino, E.S.; Santos, M.C. Qualidade de vida dos profissionais de enfermagem com dupla jornada de trabalho: uma revisão da literatura. Master's Thesis, Pontifícia Universidade Católica de Goiás, Goiânia, Goiás, Brasil. 2020. Available online: https://repositorio.pucgoias.edu.br/jspui/handle/123456789/1340 (accessed on 20 Jan 2022).

41. Sousa, M.K.P.; Lima, V.S.; Ferreira, M.T.A.; Porto, T.N.R.S.; Baldoino, L.S.; Martins, V.S.; Carvalho, D.P.; Alcântara, S.M.L. Síndrome de Burnout em profissionais da enfermagem. Rev. Eletrônica Acervo Saúde 2019, 34, e1413. https://doi.org/10.25248/reas.e141U3.2019

42. Muller, A.E.; Hafstad, E.V.; Himmels, J.P.W; Smedslund, G.; Flottorp, S.; Stensland, S.O.; Stroobants, S.; Velde, S.V.; Vist, G.E. The mental health impact of the covid-19 pandemic on healthcare workers, and interventions to help them: A rapid systematic review. Psychiatry res 2020, 293, 113441. https://doi.org/10.1016/j.psychres.2020.113441

43. Vizheh, M.; Qorbani, M.; Arzaghi, S.M.; Muhidin, S.; Javanmard, Z.; Esmaeili, M. The mental health of healthcare workers in the COVID-19 pandemic: A systematic review. J Diabetes Metab Disord 2020, 19, 1967-1978. https://doi.org/10.1007/s40200-020-00643-9

44. Frawley, T.; Van Gelderen, F.; Somanadhan, S.; Coveney, K.; Phelan, A.; Lynam-Loane, P.; De Brún, A. The impact of COVID-19 on health systems, mental health and the potential for nursing. Ir J Psychol Med 2021, 38, 220-226. https://doi.org/10.1017/ipm.2020.105

45. Koster, E.S.; Philbert, D.; Bouvy, M.L. Impact of the COVID-19 epidemic on the provision of pharmaceutical care in community pharmacies. Res. soc. adm. pharm 2021, 17, 2002-2004. https://doi.org/10.1016/j.sapharm.2020.07.001

46. Spoorthy, M.S.; Pratapa, S.K.; Mahant, S. Mental health problems faced by healthcare workers due to the COVID-19 pandemic - a review. Asian journal of psychiatry 2020, 51, 102119. https://doi.org/10.1016/j.ajp.2020.102119

47. Efendi, F.; Kurniati, A.; Bushy, A.; Gunawan, J. Concept analysis of nurse retention. Nurs. health sci 2019, 21, 422-427. https://doi.org/10.1111/nhs.12629

48. Giménez-Espert, M.D.C.; Prado-Gascó, V.; Soto-Rubio, A. Psychosocial Risks, Work Engagement, and Job Satisfaction of Nurses During COVID-19 Pandemic. Front Public Health 2020, 8, 566896. https://doi.org/10.3389/fpubh.2020.566896

49. Oliveira, W.A.; Oliveira-Cardoso, E.A.; Silva, J.L.; Santos, M.A. Impactos psicológicos e ocupacionais das sucessivas ondas recentes de pandemias em profissionais da saúde: revisão integrativa e lições aprendidas. Estud. psicol. (Campinas) 2020, 37, e200066. https://doi.org/10.1590/1982-0275202037e200066

50. Montalbán, R.L.R.; Lugo, M.M.; Soria M.S. Organizational Justice, Work engagement and Organizational Citizenship Behaviors: A winning Combination. Univ. psychol 2014, 13, 961-974. https://doi.org/10.11144/Javeriana.UPSY13-3.joet

51. Li, H.; Shi Y; Li, Y.; Xing, Z.; Wang, S.; Ying, J.; Zhang M.; Sun, J. Relationship between nurse psychological empowerment and job satisfaction: A systematic review and meta-analysis. J. adv. nurs 2018, 74, 1264-1277. https://doi.org/10.1111/jan.13549 